\title{
Primary adrenal insufficiency is associated with impaired natural killer cell function: a potential link to increased mortality
}

\author{
Irina Bancos 1,2, *, Jon Hazeldine 3,4, *, Vasileios Chortis ${ }^{1,5}$, Peter Hampson ${ }^{3,4}$, \\ Angela E Taylor ${ }^{1,5}$, Janet M Lord ${ }^{3,4}$ and Wiebke Arlt ${ }^{1,5}$ \\ ${ }^{1}$ Institute of Metabolism and Systems Research, University of Birmingham, Birmingham, UK, ${ }^{2}$ Division of \\ Endocrinology, Diabetes, Metabolism, and Nutrition, Department of Internal Medicine, Mayo Clinic, \\ Rochester, Minnesota, USA, ${ }^{3}$ Institute of Inflammation and Ageing, ${ }^{4}$ Medical Research Council-Arthritis \\ Research UK (MRC-ARUK) Centre for Musculoskeletal Ageing Research, University of Birmingham, \\ Birmingham, UK, and ${ }^{5}$ Centre for Endocrinology, Diabetes and Metabolism, Birmingham Health \\ Partners, Birmingham, UK \\ *(I Bancos and J Hazeldine contributed equally to this work)
}

\author{
Correspondence \\ should be addressed \\ to W Arlt \\ Email \\ w.arlt@bham.ac.uk
}

\begin{abstract}
Objective: Mortality in patients with primary adrenal insufficiency (PAI) is significantly increased, with respiratory infections as a major cause of death. Moreover, patients with PAI report an increased rate of non-fatal infections. Neutrophils and natural killer (NK) cells are innate immune cells that provide frontline protection against invading pathogens. Thus, we compared the function and phenotype of NK cells and neutrophils isolated from PAI patients and healthy controls to ascertain whether altered innate immune responses could be a contributory factor for the increased susceptibility of PAI patients to infection.

Design and methods: We undertook a cross-sectional study of 42 patients with PAI due to autoimmune adrenalitis $(n=37)$ or bilateral adrenalectomy $(n=5)$ and 58 sex- and age-matched controls. A comprehensive screen of innate immune function, consisting of measurements of neutrophil phagocytosis, reactive oxygen species production, NK cell cytotoxicity (NKCC) and NK cell surface receptor expression, was performed on all subjects.

Results: Neutrophil function did not differ between PAI and controls. However, NKCC was significantly reduced in PAI $(12.0 \pm 1.5 \%$ vs $21.1 \pm 2.6 \%, P<0.0001)$. Phenotypically, the percentage of NK cells expressing the activating receptors NKG2D and NKp46 was significantly lower in PAl, as was the surface density of NKG2D (all $P<0.0001$ ). Intracellular granzyme B expression was significantly increased in NK cells from PAI patients $(P<0.01)$.

Conclusions: Adrenal insufficiency is associated with significantly decreased NKCC, thereby potentially compromising early recognition and elimination of virally infected cells. This potential impairment in anti-viral immune defense may contribute to the increased rate of respiratory infections and ultimately mortality in PAI.
\end{abstract}

\section{Introduction}

Primary adrenal insufficiency (PAI), or Addison's disease, is characterized by the insufficient production of mineralocorticoids, glucocorticoids and androgen precursors by the adrenal cortex. Daily corticosteroid replacement therapy is the standard treatment for adrenal failure, and since its introduction following the
Nobel Prize-winning achievements of Kendall, Hench and Reichstein (1), the life expectancy of PAI patients has increased considerably $(2,3)$. However, despite ready availability of corticosteroid replacement, Addison's patients not only suffer from a suboptimal quality of life $(4,5)$ but also from an increased risk of premature 
death, with infections reported as a major cause $(6,7)$. A population-based, retrospective, observational study in patients with Addison's disease (6) found a two-fold increased risk ratio for death and a five times higher mortality rate from infections than in the general population, with pneumonia being the major cause of infection-related death. In line with these observations, Erichsen et al. (7) subsequently reported an increased standard mortality rate (SMR) for PAI patients, with infections being the cause of death in $10 \%$ of these patients, compared to $6 \%$ in the general population. Infectious diseases have also been documented as a main cause of death in patients with secondary adrenal insufficiency due to hypopituitarism, when compared to hypopituitarism patients with normal hypothalamicpituitary-adrenal axis function (SMR 8.88) (8).

Infection is an acute process that triggers a cytokinemediated inflammatory stress response including an increased requirement for glucocorticoid activity; therefore, in adrenal insufficiency, a superimposed adrenal crisis can contribute to the observed increase in mortality arising from infections. Indeed, most of adrenal crises are precipitated by an infection as the trigger, and in the majority of cases, underlying viral infections have been documented $(3,9)$. Patients with adrenal insufficiency have also been reported to suffer from an increased rate of non-fatal infections, with a 1.5 -fold increased risk of use of anti-microbial agents and a 4.0- to 5.0-fold increased risk of hospital admission for infection (10), with rates of pneumonia reported to be more than nine times higher in adrenal insufficiency patients. However, despite these well-documented reports about increased incidence and severity of infection among PAI patients, it is currently unknown as to why these individuals succumb more readily to infections when compared to the general population.

Neutrophils and natural killer (NK) cells are critical effector cells of the innate immune system and serve as the first line of defense against viral, fungal and bacterial infections. We hypothesized that an impairment in the function of either or both of these major cell types underlies the increased susceptibility of PAI patients to infection. Neutrophils provide immediate frontline anti-microbial protection by phagocytosis of microbes and the generation of reactive oxygen species (ROS), whereas NK cell-mediated elimination of virus-infected cells is achieved primarily through contact-dependent cytotoxicity. Thus, the objective of this cross-sectional study was to examine the innate immune response in adrenal insufficiency. To this end, we analyzed both the function and surface phenotype of neutrophils and NK cells in a cohort of patients with PAI receiving chronic corticosteroid replacement in comparison to sex- and agematched healthy controls.

\section{Subjects and methods}

\section{Subjects}

We carried out a cross-sectional study with prospective enrolment of patients with an established diagnosis of PAI and sex- and age-matched healthy controls, with total recruitment taking place over a period of 18 months. Exclusion criteria were acute illness, immunological disease, significant comorbidities likely to influence immune function and intake of drugs that are known to affect steroid synthesis, metabolism or immunity. Subjects provided written informed consent prior to the enrolment and after the approval of the study protocol by the local research ethics committee. Blood samples were taken in the morning (09:00-11:30 h), which in the PAI patients equated to $2-5 \mathrm{~h}$ after intake of their regular morning glucocorticoid replacement dose. In addition to taking a detailed history during the study visit, medical records were reviewed to obtain clinical information.

\section{Steroid hormone analysis}

Steroids were extracted from $200 \mu \mathrm{L}$ of serum by liquid/ liquid extraction using MTBE (tert-methyl butyl ether) as described previously (11). DHEA sulfate (DHEAS) was extracted from $20 \mu \mathrm{L}$ of serum after protein precipitation as described by Chadwick et al. (12).

A Waters Xevo Mass Spectrometer with an electrospray ionization source (in positive ionization mode) and an attached Acquity liquid chromatography system was used to identify and quantify the steroids. Steroids were eluted using a HSS T3, $1.8 \mu \mathrm{m}, 1.2 \times 50 \mathrm{~mm}$ column using an optimized methanol/water $0.1 \%$ formic acid gradient system. After initial analysis, samples were evaporated and derivatized to form oxime derivatives to improve the sensitivity to DHEA.

For accurate quantitation using liquid chromatography-tandem mass spectrometry, two mass transitions for each steroid analyte and its isotopically labeled internal standard were defined, followed by quantification facilitated by referring to a calibration series spanning the expected concentration range for unconjugated steroids, $0.25-500 \mathrm{ng} / \mathrm{mL}$, and for DHEA sulfate (DHEAS), $0.25-10 \mu \mathrm{g} / \mathrm{mL}$. 


\section{Isolation of immune cells}

Peripheral blood mononuclear cells (PBMCs) were isolated from whole blood by Ficoll density gradient centrifugation. NK cells were isolated from PBMCs by negative selection using magnetic assisted cell sorting (MACS) technology according to manufacturer's instructions (Miltenyi Biotec, Gladbach, Germany). NK cells routinely constituted $\geq 96 \%$ of the isolated cell population.

\section{Assessment of neutrophil function and surface phenotype}

Measurement of neutrophil phagocytosis and reactive oxygen species (ROS) production

Following manufacturer's instructions of the commercially available PhagoTEST and PhagoBURST kits (BD Biosciences), neutrophil phagocytosis of opsonized Escherichia coli (E. coli) and ROS production in response to E. coli stimulation respectively, were measured in $100 \mu \mathrm{L}$ aliquots of heparinized whole blood. For both assays, 10000 neutrophils were analyzed on an Accuri C6 flow cytometer and data were evaluated using CFlow software (BD Biosciences). Phagocytosis was recorded as the percentage of neutrophils that had phagocytosed bacteria and the number of bacteria engulfed per cell (mean fluorescent intensity (MFI)). Using both measures, the phagocytic index (PI) of neutrophils was calculated as (\% of neutrophils that had ingested bacteria/100) $\times$ MFI.

\section{CD16 surface expression}

$100 \mu \mathrm{L}$ aliquots of heparinized whole blood were immunostained for $20 \mathrm{~min}$ on ice with $4 \mu \mathrm{g} / \mathrm{mL}$ CD16-APCconjugated antibody (Clone 3G8; BD Biosciences) or its concentration-matched isotype control. After incubation, red blood cells were lysed (BD FACS Lyse solution, BD Biosciences), samples were washed in phosphate-buffered saline (PBS) and CD16 expression on 10000 neutrophils was analyzed on an Accuri C6 flow cytometer.

\section{Assessment of natural killer (NK) cell function and surface phenotype}

Phenotypic analysis of PBMC samples

PBMCs $\left(2 \times 10^{5}\right)$ were immunostained on ice for $20 \mathrm{~min}$ with combinations of the following fluorochromeconjugated mouse monoclonal antibodies or their concentration-matched isotype controls: $1 \mu \mathrm{g} / \mathrm{mL}$
CD3-Pacific Blue (Clone UCHT1; BD Biosciences), $1 \mu \mathrm{g} / \mathrm{mL}$ CD3-PeCy7 (Clone UCHT1; eBioscience, Hatfield, UK), $1 \mu \mathrm{g} / \mathrm{mL}$ CD56-PE (Clone AF12-7H3; Miltenyi Biotec), $5 \mu \mathrm{g} / \mathrm{mL}$ NKp46-Pacific Blue (Clone 9E2; BioLegend, Cambridge, UK) or $10 \mu \mathrm{g} / \mathrm{mL}$ NKG2D-PeCy7 (Clone 1D11; BioLegend). After incubation, samples were washed in PBS prior to flow cytometric analysis on a CyAN $\mathrm{ADP}_{\mathrm{Ap}}$ cytometer (Dako, Cambridgeshire, UK) where receptor expression was studied on $5000 \mathrm{CD}^{-}{ }^{-}$CD56 $6^{\mathrm{DIM}} \mathrm{NK}$ cells.

\section{Measurement of NK cell activating receptor expression on isolated NK cells}

Resting NK cells $\left(2 \times 10^{5}\right)$ were immunostained for $20 \mathrm{~min}$ on ice with $5 \mu \mathrm{g} / \mathrm{mL}$ of purified mouse anti-human NKp30 antibody (Clone P30-15; BioLegend) or its concentrationmatched isotype control (Clone MOPC-21; BioLegend). After a single wash in PBS, samples were resuspended in $\mathrm{PBS} / 1 \%$ bovine serum albumin (BSA) containing 20\% (vol/ vol) goat serum (Sigma-Aldrich) and incubated for $20 \mathrm{~min}$ on ice, after which cells were washed in PBS and pellets were resuspended in PBS/1\%BSA containing $10 \mu \mathrm{g} / \mathrm{mL}$ of FITC goat anti-mouse IgG (Clone Poly4053; BioLegend). After a 20-min incubation on ice, cells were washed in PBS and analyzed on a CyAN $\mathrm{ADP}_{\mathrm{AP}}$ cytometer, where $10000 \mathrm{NK}$ cells were assessed.

Intracellular staining for the assessment of perforin and granzyme $B$ expression

Resting NK cells $\left(2 \times 10^{5}\right)$ were fixed for $30 \mathrm{~min}$ at room temperature (RT) in fixation medium (Life Technologies). After incubation, samples were washed in PBS and resuspended in permeabilization medium (Life Technologies) that contained $10 \mu \mathrm{g} / \mathrm{mL}$ of a FITCconjugated monoclonal antibody against human perforin (Clone $\delta \mathrm{G} 9$; BioLegend), $16 \mu \mathrm{g} / \mathrm{mL}$ of a FITC-conjugated monoclonal antibody against human granzyme B (Clone GB11; BioLegend) or their concentration-matched isotype controls. Samples were incubated for $30 \mathrm{~min}$ at RT and then washed in PBS prior to flow cytometric analysis, where on a CyAN $\mathrm{ADP}_{\mathrm{AD}}$ cytometer (Dako), $10000 \mathrm{NK}$ cells were studied.

\section{NK cell cytotoxicity (NKCC) assay}

NKCC was assessed using a modified version of the protocol described by Godoy-Ramirez et al. (13). Briefly, K562 target cells were cultured either alone or with NK cells at an effector:target (E:T) cell ratio of 10:1 for 
$4 \mathrm{~h}$ at $37^{\circ} \mathrm{C}$ in a humidified $5 \% \mathrm{CO}_{2}$ atmosphere. After incubation, cells were pelleted and resuspended in PBS/1\%BSA containing 0.3 $\mu \mathrm{g}$ anti-CD56 PE (Miltenyi Biotec). Following a 10-min incubation on ice, samples were washed in PBS and stained for 5 min with $125 \mathrm{nM}$ of the dead cell stain sytox blue (Life Technologies) prior to flow cytometric analysis.

To measure NKCC, the number of lysed K562 target cells (defined as sytox blue positive) in a total population of 2000 was recorded. From here, the percentage of specific cell lysis was calculated as: (TL-SL/2000) $\times 100$, where TL is the number of lysed target cells in NK-K562 co-culture samples and SL is the number of K562 cells that underwent lysis when cultured with media alone. To measure the target cell-NK cell conjugate formation rate, conjugates were defined as K562 cells exhibiting positive PE fluorescence and the number in a population of 2000 K562 cells was recorded.

\section{Statistical analysis}

Statistical analyses were performed using GraphPad Prism software (GraphPad Software Ltd) and JMP software, version 10 (SAS Institute Inc., Cary, NC, USA). Continuous data are summarized as mean and standard deviation (s.D.) or median and ranges, depending on whether or not they were normally distributed, whereas categorical data are summarized as number (\%). Associations between AI and subject characteristics were assessed using the KruskalWallis test for continuous variables and the chi-square test for categorical variables. Data distribution was examined using the Kolmogorov-Smirnov test. For data that followed a normal distribution, unpaired Student $t$ tests were performed, whereas for non-normally distributed data, a Mann-Whitney $U$ test was used. In dot plots, horizontal lines represent the median value. Statistical significance was accepted at $P \leq 0.05$.

\section{Results}

\section{Clinical phenotype and demographics in PAI patients and controls}

We recruited 43 PAI patients (35 females, 8 males) with a median age of 49 (range: 18-79) years (men: 46.5 (18-64) years; women: 49 (19-79) years) (for details see Table 1). Median BMI was $23.5(19-30) \mathrm{kg} / \mathrm{m}^{2}$ in the male patients and $25(19-41) \mathrm{kg} / \mathrm{m}^{2}$ in the women with PAI. Steroid replacement therapy consisted of hydrocortisone (median daily dose 25 (range: 10-40) mg) and fludrocortisone (daily dose 100 (50-300) $\mu \mathrm{g}$ ). Most patients were taking hydrocortisone in two separate daily doses $(27 / 43 ; 63 \%)$, with the remainder taking once-daily $(3 / 43 ; 7 \%)$ or thrice-daily doses $(13 / 43 ; 30 \%)$. Eleven of the 35 women with PAI were on long-standing replacement with the androgen precursor DHEA (daily dose: 25 (2550) $\mathrm{mg}$ ), and intake was confirmed by circulating serum DHEAS (women without DHEA replacement 0.2 (0.1$0.2) \mu \mathrm{mol} / \mathrm{L}$ vs $6.7(3.2-8.3) \mu \mathrm{mol} / \mathrm{L}$ in women on DHEA replacement; $P<0.0001$ ).

Underlying cause of disease in the PAI patients was autoimmune adrenalitis $(n=37 ; 15$ patients with isolated autoimmune Addison's disease, 22 with autoimmune polyglandular syndrome type 2, APS2), permanent glucocorticoid deficiency after adrenalectomy for Cushing syndrome in one patient and bilateral adrenalectomy in the five remaining patients. Duration of PAI since diagnosis was established for the first time was $13(0.5-49)$ years. Comorbidities in the 22 patients with APS2 included autoimmune thyroid disease $(n=18)$, pernicious anemia $(n=3)$, premature ovarian failure $(n=4)$, type 1 diabetes $(n=2)$, vitiligo $(n=2)$ and asthma $(n=2)$. All APS2 patients had a family history of autoimmunity comprising thyroid disease $(n=18)$, ulcerative colitis/Crohn's disease $(n=5)$, type 1 diabetes mellitus $(n=4)$, vitiligo $(n=3)$, PAI $(n=2)$ and pernicious anemia $(n=1)$.

We recruited 27 healthy controls, 12 men with a median age of 41 (31-61) years and 15 women aged 42 (34-50) years. In addition, we recruited 31 patients from the Birmingham 1000 Elders cohort http://www. birmingham.ac.uk/research/activity/mds/centres/ healthy-ageing/elders.aspx as healthy elderly controls (age: 73 (62-91) years).

\section{Neutrophil function in PAl is normal}

ROS generation and phagocytosis are two key microbicidal mechanisms of neutrophils. When challenged with immunoglobulin (Ig) and complement-coated E. coli, no difference was found in ROS generation between neutrophils from PAI patients and age- and sex-matched healthy controls (Table 2). However, a trend $(P=0.07)$ toward a reduced phagocytic index for neutrophils from PAI patients was observed (Table 2). A measure of phagocytic activity, phagocytic index, takes into account both the percentage of neutrophils that have ingested bacteria as well as their individual phagocytic activity (number of bacteria per cell). Analysis of the phagocytic 
Table 1 Clinical characteristics of the 43 patients with primary adrenal insufficiency included in this study.

\begin{tabular}{|c|c|c|c|c|c|c|c|c|c|}
\hline $\begin{array}{l}\text { Patient } \\
\text { number }\end{array}$ & $\begin{array}{l}\text { Sex } \\
(\mathrm{F} / \mathrm{M})\end{array}$ & $\begin{array}{l}\text { Age } \\
\text { (years) }\end{array}$ & $\begin{array}{c}\text { Body mass } \\
\text { index } \\
\left(\mathrm{kg} / \mathrm{m}^{2}\right)\end{array}$ & $\begin{array}{l}\text { Hydro- } \\
\text { cortisone } \\
\text { daily dose } \\
(\mathrm{mg})\end{array}$ & $\begin{array}{l}\text { Number } \\
\text { of daily } \\
\text { hydro- } \\
\text { cortisone } \\
\text { doses }\end{array}$ & $\begin{array}{l}\text { Fludro-cortisone } \\
\text { once daily dose } \\
\text { (g) }\end{array}$ & $\begin{array}{c}\text { DHEA } \\
\text { once daily } \\
\text { dose }(\mathrm{mg})\end{array}$ & $\begin{array}{l}\text { Duration } \\
\text { of disease } \\
\text { (years) }\end{array}$ & $\begin{array}{l}\text { Cause of primary adrenal } \\
\text { insufficiency }\end{array}$ \\
\hline 1 & $\mathrm{~F}$ & 19 & 28.3 & 20 & 3 & 150 & - & 3 & Polyglandular syndrome type 2 \\
\hline 2 & $\mathrm{~F}$ & 20 & 19.0 & 20 & 2 & 150 & - & 4 & Polyglandular syndrome type 2 \\
\hline 3 & $\mathrm{~F}$ & 28 & 32.3 & 20 & 2 & 200 & 25 & 9 & Polyglandular syndrome type 2 \\
\hline 4 & $\mathrm{~F}$ & 30 & 34.5 & 25 & 2 & 100 & - & 11 & Isolated Addison's disease \\
\hline 5 & $\mathrm{~F}$ & 35 & 21.2 & 25 & 2 & 100 & - & 12 & Isolated Addison's disease \\
\hline 6 & $\mathrm{~F}$ & 35 & 23.0 & 25 & 2 & 200 & 25 & 11 & Isolated Addison's disease \\
\hline 7 & $\mathrm{~F}$ & 36 & 26.5 & 30 & 2 & 250 & - & 23 & Isolated Addison's disease \\
\hline 8 & $\mathrm{~F}$ & 40 & 21.9 & 20 & 2 & 150 & - & 17 & Polyglandular syndrome type 2 \\
\hline 9 & $\mathrm{~F}$ & 40 & 29.0 & 25 & 2 & 150 & 37.5 & 5 & Polyglandular syndrome type 2 \\
\hline 10 & $\mathrm{~F}$ & 40 & 37.2 & 20 & 2 & 300 & - & 27 & Isolated Addison's disease \\
\hline 11 & $\mathrm{~F}$ & 42 & 22.1 & 25 & 2 & 125 & - & 11 & Polyglandular syndrome type 2 \\
\hline 12 & $\mathrm{~F}$ & 42 & 41.0 & 20 & 1 & & - & 13 & Isolated Addison's disease \\
\hline 13 & $\mathrm{~F}$ & 44 & 35.0 & 40 & 3 & 100 & - & 1 & Isolated Addison's disease \\
\hline 14 & $\mathrm{~F}$ & 45 & 23.3 & 15 & 2 & 50 & 50 & 14 & Polyglandular syndrome type 2 \\
\hline 15 & $\mathrm{~F}$ & 46 & 22.9 & 30 & 2 & 100 & - & 3 & Polyglandular syndrome type 2 \\
\hline 16 & $\mathrm{~F}$ & 48 & 23.0 & 25 & 3 & 100 & - & 20 & Polyglandular syndrome type 2 \\
\hline 17 & $\mathrm{~F}$ & 49 & 20.3 & 25 & 2 & 150 & - & 26 & Polyglandular syndrome type 2 \\
\hline 18 & $\mathrm{~F}$ & 53 & 23.0 & 20 & 3 & 100 & 25 & 12 & Isolated Addison's disease \\
\hline 19 & $\mathrm{~F}$ & 54 & 27.4 & 30 & 2 & 50 & 25 & 17 & Polyglandular syndrome type 2 \\
\hline 20 & $\mathrm{~F}$ & 55 & 23.0 & 20 & 2 & 100 & 25 & 13 & Polyglandular syndrome type 2 \\
\hline 21 & $\mathrm{~F}$ & 56 & 21.0 & 30 & 2 & 200 & - & 11 & Isolated Addison's disease \\
\hline 22 & $\mathrm{~F}$ & 56 & 29.4 & 22.5 & 3 & 250 & - & 30 & Polyglandular syndrome type 2 \\
\hline 23 & $\mathrm{~F}$ & 60 & 21.2 & 25 & 3 & 100 & 37.5 & 12 & Polyglandular syndrome type 2 \\
\hline 24 & $\mathrm{~F}$ & 63 & 24.7 & 10 & 1 & 100 & - & 28 & Polyglandular syndrome type 2 \\
\hline 25 & $\mathrm{~F}$ & 63 & 21.0 & 15 & 2 & 50 & - & 18 & Polyglandular syndrome type 2 \\
\hline 26 & $\mathrm{~F}$ & 67 & 29.3 & 20 & 2 & 100 & 25 & 30 & Polyglandular syndrome type 2 \\
\hline 27 & $\mathrm{~F}$ & 69 & 24.4 & 30 & 2 & 100 & - & 49 & Isolated Addison's disease \\
\hline 28 & $\mathrm{~F}$ & 71 & 25.3 & 20 & 1 & 100 & - & 31 & Polyglandular syndrome type 2 \\
\hline 29 & $\mathrm{~F}$ & 73 & 25.0 & 20 & 3 & & - & 3 & Polyglandular syndrome type 2 \\
\hline 30 & $\mathrm{~F}$ & 77 & 26.6 & 20 & 3 & 100 & - & 24 & Polyglandular syndrome type 2 \\
\hline 31 & $\mathrm{~F}$ & 79 & 28.0 & 30 & 3 & 50 & - & 38 & Isolated Addison's disease \\
\hline 32 & $\mathrm{~F}$ & 43 & 18.8 & 30 & 2 & 250 & 25 & 1 & Bilateral adrenalectomy \\
\hline 33 & $\mathrm{~F}$ & 49 & 25.0 & 25 & 2 & 150 & - & 7 & Bilateral adrenalectomy \\
\hline 34 & $\mathrm{~F}$ & 64 & 25.0 & 20 & 3 & 100 & - & 12 & Bilateral adrenalectomy \\
\hline 35 & $\mathrm{~F}$ & 55 & 31.7 & 20 & 2 & - & 50 & 27 & Adrenalectomy for Cushing \\
\hline 36 & M & 18 & 22.1 & 25 & 3 & 150 & - & 1 & Isolated Addison's disease \\
\hline 37 & M & 19 & 19.4 & 25 & 2 & 100 & - & 1 & Polyglandular syndrome type 2 \\
\hline 38 & M & 38 & 23.0 & 40 & 3 & 150 & - & 14 & Isolated Addison's disease \\
\hline 39 & M & 59 & 20.6 & 30 & 3 & 150 & - & 8 & Polyglandular syndrome type 2 \\
\hline 40 & M & 63 & 28.0 & 30 & 2 & 100 & - & 29 & Isolated Addison's disease \\
\hline 41 & M & 64 & 30.0 & 30 & 2 & 150 & - & 29 & Isolated Addison's disease \\
\hline 42 & M & 30 & 24.0 & 30 & 2 & 300 & - & 6 & Bilateral adrenalectomy \\
\hline 43 & M & 55 & 28.2 & 25 & 2 & 100 & - & 4 & Bilateral adrenalectomy \\
\hline
\end{tabular}

activity revealed a trend $(P=0.08)$ toward reduced phagocytic activity of neutrophils from PAI patients, with no difference found in respect to the percentage of neutrophils capable of ingesting E.coli (Table 2).

Surface expression of the $\mathrm{F}_{\mathrm{C}}$ receptor CD16 is critical for neutrophils to phagocytose Ig-coated pathogens. Thus, having observed a trend for impaired phagocytosis by neutrophils from PAI patients, we compared surface expression of CD16 on neutrophils isolated from patients and healthy sex- and age-matched controls, which, however, revealed no difference between PAI patients and controls (Table 2).

\section{Natural killer cell cytotoxicity is decreased in PAI}

NK cells rapidly eliminate virally infected cells via contact-dependent cytotoxicity, which begins with conjugate formation between NK cells and the infected 
Table 2 Neutrophil phagocytosis, reactive oxygen species (ROS) generation and surface CD16 expression in 42 PAI patients and 27 healthy, sex- and age-matched controls. For the assessment of CD16 expression, 41 PAI patients and 27 healthy controls were studied. Values are presented as mean \pm standard deviation.

\begin{tabular}{|c|c|c|c|}
\hline & PAl patients & Healthy controls & $\boldsymbol{P}$ \\
\hline Phagocytic index & $257252 \pm 87162$ & $299220 \pm 98779$ & 0.07 \\
\hline$\%$ Phagocytosing neutrophils & $98.0 \pm 1.5$ & $98.2 \pm 1.2$ & 0.68 \\
\hline Phagocytic activity (MFI) & $262469 \pm 88707$ & $304941 \pm 100876$ & 0.08 \\
\hline ROS generation (MFI) & $57023 \pm 26463$ & $49915 \pm 19302$ & 0.23 \\
\hline$\% \mathrm{CD} 16^{+}$neutrophils & $97.46 \pm 1.82$ & $96.63 \pm 3.04$ & 0.33 \\
\hline CD16 surface density & $58775 \pm 27559$ & $68380 \pm 31401$ & 0.20 \\
\hline
\end{tabular}

MFI, median fluorescence intensity. Phagocytic index calculated as (\% phagocytosis/100) $\times$ phagocytic activity.

target cell. Through the use of two-color flow cytometry, we performed a simultaneous assessment of conjugate formation and natural killer cell cytotoxicity (NKCC). NK cells from PAI patients exhibited significantly reduced cytotoxicity toward transformed cells when compared to NK cells from healthy controls (PAI: $12.0 \pm 1.5 \%$ vs $21.1 \pm 2.6 \%$ in controls, $P<0.0001$ ) (Fig. 1A), whereas both groups exhibited similar ability for NK cell-target cell conjugate formation (Fig. 1B).

\section{Natural killer granzyme B expression is increased in PAI}

Granule exocytosis is the predominant mechanism by which NK cells mediate target cell lysis. Two molecules
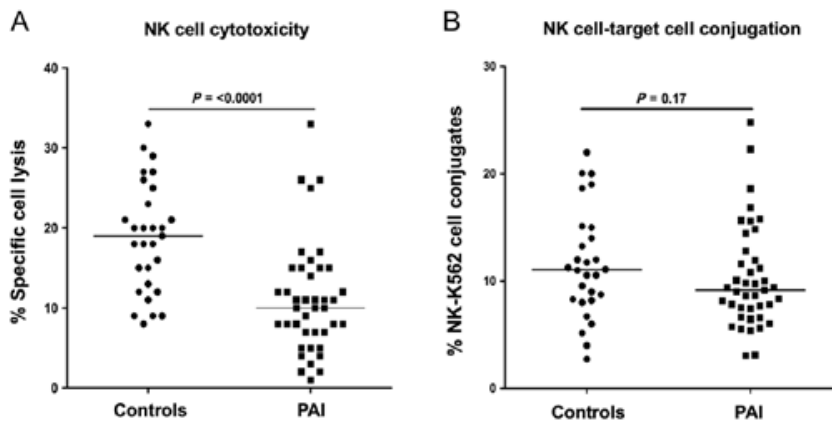

Figure 1

Natural killer cell cytotoxicity and conjugate formation. Panel A, cytotoxicity of resting NK cells isolated from PAI patients $(n=41)$ and age- and sex-matched healthy controls $(n=29)$ toward the erythroleukemic K562 cell line at an effector:target cell ratio of 10:1. Horizontal line depicts the median value. Panel B, percentage of NK cells bound to K562 tumor cells as a measure of conjugate formation between effector (NK) and target (K562) cells. Conjugate formation was assessed following a 4-h co-culture at an effector:target cell ratio of 10:1. Data were obtained from 41 PAI patients and 28 age- and sex-matched healthy controls. Horizontal line depicts the median value. central to this form of NK cell defense are the pore-forming protein perforin and the serine protease granzyme B. We found no difference in the percentage of perforin or granzyme B-positive NK cells between PAI patients and their age- and sex-matched controls (Fig. 2A and B). Similarly, no differences were observed in the staining intensity (median fluorescence intensity) of perforin between PAI and controls (59.9 \pm 36.4 vs $47.0 \pm 28.7$; $P=0.12$ ) (Fig. 2C and E). However, the staining intensity of granzyme B was found to be significantly higher in NK cells from PAI patients than that in controls $(21.1 \pm 11.1$ vs $14.5 \pm 7.5 ; P=0.007$ ) (Fig. 2D and F).

\section{Natural killer cell-activating receptor expression is decreased in PAI}

The induction of NKCC is governed in part by signals transmitted through surface-expressed NK cell-activating receptors, which recognize ligands present on the surface of target cells. To determine whether altered NK cellactivating receptor expression could explain the impaired NKCC in PAI patients, we measured the surface expression of the NK cell-activating receptor NKG2D and the natural cytotoxicity receptors NKp30 and NKp46. Compared to healthy controls, the percentage of NK cells expressing NKG2D and NKp46 was significantly lower in PAI patients as was the surface density of NKG2D (all $P<0.0001$ ). In addition, a trend $(P=0.06)$ for a reduced frequency of NKp30-positive NK cells was observed (Table 3).

\section{Discussion}

Although infections are a common occurrence among patients with PAI $(3,9,10)$ and a major cause of the excess mortality that is observed among this patient group $(6,7)$, it is currently unknown as to why these individuals report more frequent and severe infectious episodes when compared to the general population. Here, we have carried 
A

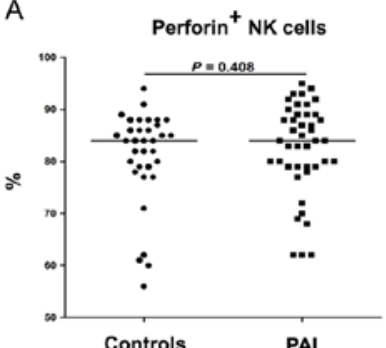

C
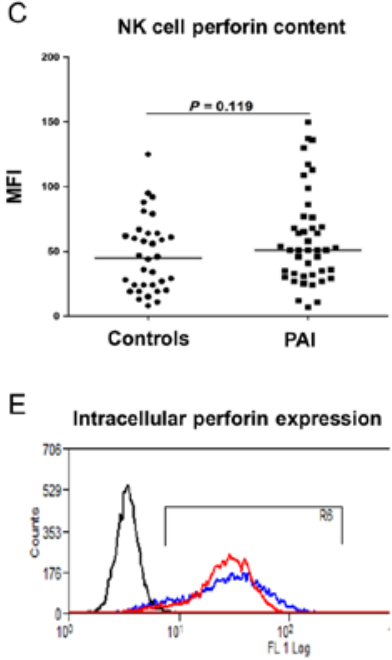

B Granzyme B $^{+}$NK cells

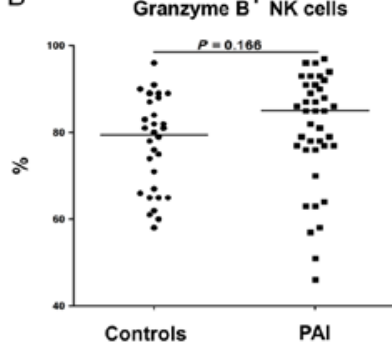

D

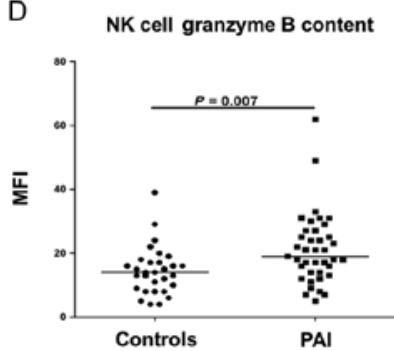

$\mathrm{F}$

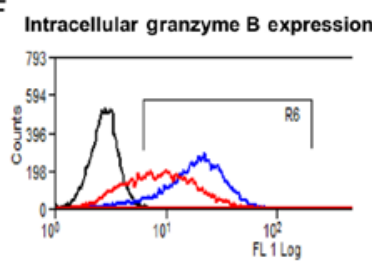

Figure 2

Intracellular perforin and granzyme B expression in resting NK cells. Panels $A$ and $C$, NK cells isolated from PAl patients $(n=42)$ and age- and sex-matched healthy controls $(n=34)$ were analyzed for intracellular perforin expression. Data are presented as percentage positive NK cells (Panel A) and staining intensity (Panel C). Horizontal line depicts the median value. Panels $B$ and $D, N K$ cells isolated from PAI patients $(n=39)$ and age- and sex-matched healthy controls $(n=30)$ were analyzed for intracellular granzyme B expression. Data are presented as percentage positive NK cells (Panel B) and staining intensity (Panel D). Horizontal line depicts the median value. MFI, mean fluorescence intensity. Panels $\mathrm{E}$ and $F$, representative flow cytometry plots depicting intracellular perforin (Panel E) and granzyme B (Panel F) expression in NK cells isolated from a single PAI patient (blue line) and healthy control (red line). The black line represents the isotype control.

out a comparative assessment of the function and surface phenotype of NK cells and neutrophils isolated from PAI patients and age- and sex-matched healthy controls in an effort to ascertain whether defects in innate immunity could explain the increased susceptibility of PAI patients to infection.

As the first immune cell to arrive at a site of infection, neutrophils provide immediate frontline protection against rapidly dividing bacteria, fungi and yeast. Based on the results of a recent study that reported an increased incidence of fungal infection in PAI patients (10), we hypothesized that neutrophils from these patients would exhibit impaired microbicidal activity when compared to healthy controls. Although no difference was found in ROS generation between the two groups, we observed a trend $(P=0.07)$ toward reduced phagocytosis of opsonized E.coli by neutrophils from PAI patients, an impairment that could negatively influence their ability to eliminate invading pathogens, though clearly this would appear not to be a major contributor to the increased incidence of infection among this group.

In contrast, we have shown for the first time that NK cells isolated from patients with PAI exhibit significantly impaired cytotoxicity at the single cell level. As NK cells are involved in the early recognition and elimination of virus-infected cells, this defect in NKCC may be one factor underlying the increased incidence and severity of viral infections reported by PAI patients (10). Interestingly, a recent report has described reduced innate anti-viral responses in PBMCs in PAI, specifically reduced CXCL9 and CXCL10 production in response to stimulation with interferon (14). Taking those findings together with our data, we are now looking at significant evidence that there is a major defect in the innate immune response in PAI, potentially increasing susceptibility to viral infections.

The adrenal androgen precursor dehydroepiandrosterone (DHEA) has been reported to increase NK cell numbers $(15,16)$, albeit mainly in rodent-based studies, which complicates matters as rodent adrenals do not produce DHEA in substantial amounts. One humanbased study has examined the immunological effects of twelve-week dehydroepiandrosterone replacement therapy in patients with PAI (17) and found that DHEA treatment reduced the frequency of NK and NKT cells. However, the study did not comment on baseline differences in NK cell function or frequency between patients and healthy controls. In our studies, we found no difference in circulating NK cell numbers between PAI patients and healthy controls, but found significantly decreased NKCC, which was equally reduced in patients with and without long-standing DHEA replacement therapy (Fig. 3A), excluding DHEA deficiency as the causative factor explaining the observed decrease in NKCC.

Glucocorticoids have been shown to potently suppress NKCC in a series of in vitro studies $(18,19,20)$. 
Table 3 Expression of activatory surface receptors on the surface of natural killer (NK) cells. For NKG2D, NK cells isolated from 42 PAI patients and 30 healthy controls were studied. For NKp30, $n=40$ for PAI patients and $n=30$ for healthy controls.

For NKp46, we studied NK cells from 42 PAI patients and 32 healthy controls. Values are presented as mean \pm standard deviation. Significant differences are indicated in bold font.

\begin{tabular}{|c|c|c|c|c|c|c|}
\hline & \multicolumn{3}{|c|}{ Percentage positive NK cells } & \multicolumn{2}{|c|}{ Surface density (MFI) } & \\
\hline & Healthy controls & PAl patients & $P$ & Healthy controls & PAl patients & $P$ \\
\hline NKG2D & $92.6 \pm 4.3$ & $78.0 \pm 11.9$ & $<0.0001$ & $34.8 \pm 7.9$ & $20.4 \pm 5.8$ & $<0.0001$ \\
\hline NKp30 & $65.6 \pm 20.5$ & $56.4 \pm 19.6$ & 0.06 & $14.5 \pm 8.8$ & $13.6 \pm 8.0$ & 0.34 \\
\hline NKp46 & $46.8 \pm 212$ & $27.9 \pm 14.0$ & $<0.0001$ & $7.6 \pm 4.0$ & $6.7 \pm 2.9$ & 0.32 \\
\hline
\end{tabular}

MFI, mean fluorescence intensity.

Current glucocorticoid replacement options are not able to mimic the physiologic circadian cortisol secretion but result in non-physiological peak and trough cortisol concentrations equating to transient over- and underreplacement, which could impact on NK cell function through altered CLOCK gene regulation of immune function. NK cells of mice with deletion of the clock gene period circadian clock 1 (Per1) display significantly altered diurnal rhythms of cytokine release and expression of the cytolytic factors perforin and granzyme $\mathrm{B}(21)$. This resonates with our finding of increased granzyme B expression in the NK cells of our PAI patients. Moreover, in a recent paper, it has been shown that oral hydrocortisone in doses of $20 \mathrm{mg}$ acutely upregulate PER1 in human peripheral blood mononuclear cells and that glucocorticoid pulses can be used to entrain an aberrant diurnal rhythm (22).

The induction of NKCC is governed in part by signals transmitted through surface-expressed germline-encoded activatory receptors (23). Upon ligand recognition, NK cell-activating receptors, which include the natural cytotoxicity receptors NKp30 and NKp46 and the C-type lectin family member NKG2D, initiate diverse signaling pathways, which provided they overcome signals from inhibitory receptors lead to NK cell activation (24). For the cytotoxicity assays performed in this study, the MHC class I-deficient erythroleukemic K562 cell line was used as the target cell. Signaling through the NK cell-activating receptor NKG2D has been shown to be primarily responsible for NK-mediated lysis of K562 cells (25). Compared to healthy controls, we found that both the frequency of NKG2D-positive NK cells and its surface density were significantly lower in PAI patients, highlighting a potential mechanistic explanation for the reduced cytotoxicity of NK cells from PAI patients against K562 cells. In addition to NKG2D, we found a significantly reduced frequency of circulating NKp46positive NK cells among PAI patients and a trend $(P=0.06)$ for a reduced percentage of NKp30-positive NK cells. Although changes in NKp46 and NKp30 expression are unlikely to be responsible for the impaired cytotoxicity against K562 cells we have described in this report (25), they may contribute to the increased susceptibility of PAI patients to infection. For example, NKp46 has been shown to directly bind the hemagglutinin of influenza virus (26) and to detect human monocytes infected with mycobacterium tuberculosis (TB) (27). Thus, a reduced frequency of NK cells expressing NKp46 may explain to some degree the increased incidence of viral infections among PAI patients (10) and may also hamper the immune response against $\mathrm{TB}$, which represents a major cause of PAI disease in the developing world. In respect of NKp30, this receptor has been shown to play an essential role in NK cell-dependent maturation of dendritic cells (DCs) (28), a professional
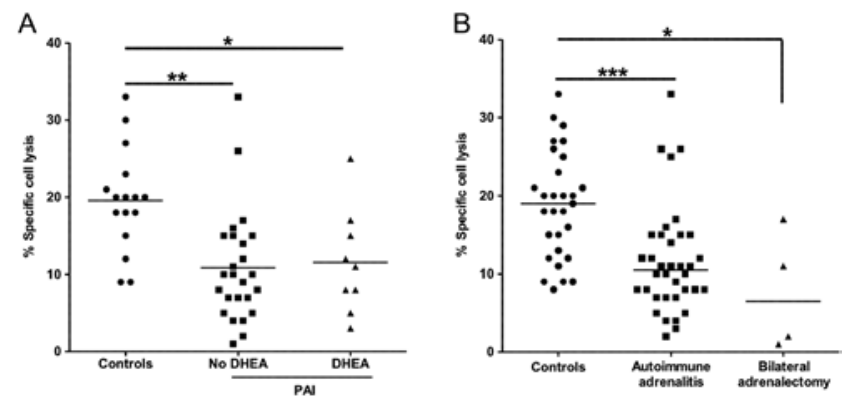

\section{Figure 3}

Natural killer cell cytotoxicity (NKCC), DHEA replacement therapy and cause of primary adrenal insufficiency (PAI). Panel A shows NKCC (median and individual data points) as assessed in healthy controls $(n=29)$ and patients with PAI $(n=41)$, separated into patients with $(n=11)$ and without $(n=30)$ chronic DHEA replacement therapy. Panel B shows NKCC (median and individual data points) in healthy controls ( $n=29)$, patients with PAI due to autoimmune adrenalitis $(n=36)$ and patients with PAl after bilateral adrenalectomy $(n=4)$. Statistical comparisons were made with a nonparametric Kruskal-Wallis test with Dunn's multiple comparison test. ${ }^{*} P<0.05 ; * * P<0.01 ; * * * P<0.001$. 
antigen-presenting cell that promotes the initiation of an adaptive immune response. Thus, it is conceivable that as a consequence of decreased NKp30 expression, the process of NK-dependent DC maturation would be impaired in PAI patients, hampering the development of an antigen-specific adaptive immune response, one consequence of which would be delayed clearance of invading pathogens.

One potential explanation for the downregulation of activatory receptors on NK cells from PAI patients is a change in epigenetic regulation. In a recent study, Bjanesoy et al. (29) identified multiple hypomethylated gene promoter regions in $\mathrm{CD}^{+} \mathrm{T}$ cells isolated from PAI patients. Given that in vitro treatment of NK cells with demethylating agents has been shown to result in decreased surface expression of NKG2D (30), it would be of interest for future studies to examine the DNA methylation profile of NK cells from PAI patients, focusing primarily upon the promoters of genes that encode NK cell activatory receptors.

Of note, the polymorphic MHC class I polypeptiderelated sequence A (MICA) molecule is a ligand for NKG2D and one of its variants, MICA5.1 or ICA*008, has been shown to be strongly associated with the risk of developing autoimmune Addison's disease (31). This would suggest that the low NKCC we observed in our PAI patient cohort may be more related to the cause than to the consequences of PAI. However, we also included patients with PAI due to bilateral adrenalectomy, i.e., patients with no underlying autoimmune disorder, and this patient group, albeit small in size, showed similar and significant decreases in NKCC (Fig. 3B) and also NKG2D expression.

Taken together, we have shown for the first time that NKCC is significantly decreased in patients with PAI, providing a potential causal link explaining increased morbidity and mortality in PAI patients as a consequence of respiratory infections. Neither cause of disease nor DHEA replacement did influence the significant reduction in NKCC in PAI patients, which leads us to propose that the lack of diurnal cortisol delivery and consequently altered peripheral CLOCK gene regulation of immune cells may be the underlying causative mechanism. It will be highly interesting to examine whether introduction of glucocorticoid replacement with a delivery mode mimicking the physiological diurnal profile including the early morning cortisol surge $(32,33)$ could reestablish normal NKCC in adrenal insufficiency and help to reduce morbidity and ultimately mortality.
Declaration of interest

W A and I B are consultants to Diurnal Ltd. All other authors have nothing to disclose.

\section{Funding}

This work was supported by the Medical Research Council UK (Program Grant 0900567, to W A), the Mayo Clinic Foundation for Education and Research (Mayo Scholarship, to I B) and the Wellcome Trust (Clinical Research Training Fellowship WT101671, to V C).

\section{References}

1 The Nobel Prize in Physiology or Medicine 1950. Nobelprize.org. Nobel Media AB 2014. Web. 28 Mar 2016.

2 Bancos I, Hahner S, Tomlinson J \& Arlt W. Diagnosis and management of adrenal insufficiency. Lancet Diabetes \& Endocrinology 20153 216-226. (doi:10.1016/S2213-8587(14)70142-1)

3 Hahner S, Loeffler M, Bleicken B, Drechsler C, Milovanovic D, Fassnacht M, Ventz M, Quinkler M \& Allolio B. Epidemiology of adrenal crisis in chronic adrenal insufficiency: the need for new prevention strategies. European Journal of Endocrinology 2010162 597-602. (doi:10.1530/EJE-09-0884)

4 Hahner S, Loeffler M, Fassnacht M, Weismann D, Koschker AC, Quinkler M, Decker O, Arlt W \& Allolio B. Impaired subjective health status in 256 patients with adrenal insufficiency on standard therapy based on cross-sectional analysis. Journal of Clinical Endocrinology \& Metabolism 200792 3912-3922. (doi:10.1210/jc.2007-0685)

5 Lovas K, Loge JH \& Husebye ES. Subjective health status in Norwegian patients with Addison"s disease. Clinical Endocrinology $2002 \mathbf{5 6}$ 581-588. (doi:10.1046/j.1365-2265.2002.01466.x)

6 Bergthorsdottir R, Leonsson-Zachrisson M, Oden A \& Johannsson G. Premature mortality in patients with Addison"s disease: a populationbased study. Journal of Clinical Endocrinology \& Metabolism 200691 4849-4853. (doi:10.1210/jc.2006-0076)

7 Erichsen MM, Lovas K, Fougner KJ, Svartberg J, Hauge ER, Bollerslev J Berg JP, Mella B \& Husebye ES. Normal overall mortality rate in Addison"s disease, but young patients are at risk of premature death. European Journal of Endocrinology 2009160 233-237. (doi:10.1530/EJE08-0550)

8 Burman P, Mattsson AF, Johannsson G, Hoybye C, Holmer H, Dahlqvist P, Berinder K, Engstrom BE, Ekman B, Erfurth EM et al. Deaths among adult patients with hypopituitarism: hypocortisolism during acute stress, and de novo malignant brain tumors contribute to an increased mortality. Journal of Clinical Endocrinology \& Metabolism 201398 1466-1475. (doi:10.1210/jc.2012-4059)

9 Hahner S, Spinnler C, Fassnacht M, Burger-Stritt S, Lang K, Milovanovic D, Beuschlein F, Willenberg HS, Quinkler M \& Allolio B. High incidence of adrenal crisis in educated patients with chronic adrenal insufficiency: a prospective study. Journal of Clinical Endocrinology \& Metabolism 2015100 407-416. (doi:10.1210/jc.20143191)

10 Smans LC, Souverein PC, Leufkens HG, Hoepelman AI \& Zelissen PM. Increased use of antimicrobial agents and hospital admission for infections in patients with primary adrenal insufficiency: a cohort study. European Journal of Endocrinology 2013168 609-614. (doi:10.1530/EJE-12-0879)

11 O'Reilly MW, Taylor AE, Crabtree NJ, Hughes BA, Capper F, Crowley RK, Stewart PM, Tomlinson JW \& Arlt W. Hyperandrogenemia predicts metabolic phenotype in polycystic ovary syndrome: the utility of serum androstenedione. Journal of Clinical Endocrinology \& Metabolism 201499 1027-1036.

12 Chadwick CA, Owen LJ \& Keevil BG. Development of a method for the measurement of dehydroepiandrosterone sulphate by liquid 
chromatography-tandem mass spectrometry. Annals of Clinical Biochemistry 200542 468-474. (doi:10.1258/000456305774538175)

13 Godoy-Ramirez K, Franck K \& Gaines H. A novel method for the simultaneous assessment of natural killer cell conjugate formation and cytotoxicity at the single-cell level by multi-parameter flow cytometry. Journal of Immunological Methods 2000239 35-44. (doi:10.1016/S0022-1759(00)00161-7)

14 Edvardsen K, Bjanesoy T, Hellesen A, Breivik L, Bakke M, Husebye ES $\&$ Bratland E. Peripheral blood cells from patients with autoimmune Addison"s disease poorly respond to interferons in vitro, despite elevated serum levels of interferon-inducible chemokines. Journal of Interferon \& Cytokine Research 201535 759-770. (doi:10.1089/ jir.2014.0171)

15 Rutkowski K, Sowa P, Rutkowska-Talipska J, Kuryliszyn-Moskal A \& Rutkowski R. Dehydroepiandrosterone (DHEA): hypes and hopes. Drugs 201474 1195-1207. (doi:10.1007/s40265-014-0259-8)

16 Hazeldine J, Arlt W \& Lord JM. Dehydroepiandrosterone as a regulator of immune cell function. Journal of Steroid Biochemistry and Molecular Biology 2010120 127-136. (doi:10.1016/j. jsbmb.2009.12.016)

17 Coles AJ, Thompson S, Cox AL, Curran S, Gurnell EM \& Chatterjee VK. Dehydroepiandrosterone replacement in patients with Addison's disease has a bimodal effect on regulatory $(\mathrm{CD} 4+\mathrm{CD} 25 \mathrm{hi}$ and CD4+FoxP3+) T cells. European Journal of Immunology 200535 3694-3703. (doi:10.1002/eji.200526128)

18 Mavoungou E, Bouyou-Akotet MK \& Kremsner PG. Effects of prolactin and cortisol on natural killer (NK) cell surface expression and function of human natural cytotoxicity receptors (NKp46, NKp44 and NKp30). Clinical \& Experimental Immunology 2005139 287-296. (doi:10.1111/j.1365-2249.2004.02686.x)

19 Gatti G, Cavallo R, Sartori ML, del Ponte D, Masera R, Salvadori A, Carignola R \& Angeli A. Inhibition by cortisol of human natural killer (NK) cell activity. Journal of Steroid Biochemistry and Molecular Biology 198726 49-58. (doi:10.1016/0022-4731(87)90030-6)

20 Duggal NA, Upton J, Phillips AC, Hampson P \& Lord JM. NK cell immunesenescence is increased by psychological but not physical stress in older adults associated with raised cortisol and reduced perforin expression. Age 201537 9748. (doi:10.1007/s11357-0159748-2)

21 Logan RW, Wynne O, Levitt D, Price D \& Sarkar DK. Altered circadian expression of cytokines and cytolytic factors in splenic natural killer cells of Per1(-/-) mutant mice. Journal of Interferon \& Cytokine Research 201333 108-114. (doi:10.1089/jir.2012.0092)

22 Cuesta M, Cermakian N \& Boivin DB. Glucocorticoids entrain molecular clock components in human peripheral cells. FASEB Journal 201529 1360-1370. (doi:10.1096/fj.14-265686)

23 Lanier LL. NK cell recognition. Annual Review of Immunology 200523 225-274. (doi:10.1146/annurev.immunol.23.021704.115526)
24 MacFarlane AWt \& Campbell KS. Signal transduction in natural killer cells. Current Topics in Microbiology and Immunology 2006298 23-57. (doi:10.1007/3-540-27743-9_2)

25 Epling-Burnette PK, Bai F, Painter JS, Rollison DE, Salih HR, Krusch M, Zou J, Ku E, Zhong B, Boulware D et al. Reduced natural killer (NK) function associated with high-risk myelodysplastic syndrome (MDS) and reduced expression of activating NK receptors. Blood 2007109 4816-4824. (doi:10.1182/blood-2006-07-035519)

26 Mandelboim O, Lieberman N, Lev M, Paul L, Arnon TI, Bushkin Y, Davis DM, Strominger JL, Yewdell JW \& Porgador A. Recognition of haemagglutinins on virus-infected cells by NKp46 activates lysis by human NK cells. Nature 2001409 1055-1060. (doi:10.1038/35059110)

27 Garg A, Barnes PF, Porgador A, Roy S, Wu S, Nanda JS, Griffith DE, Girard WM, Rawal N, Shetty S et al. Vimentin expressed on Mycobacterium tuberculosis-infected human monocytes is involved in binding to the NKp46 receptor. Journal of Immunology $2006 \mathbf{1 7 7}$ 6192-6198. (doi:10.4049/jimmunol.177.9.6192)

28 Vitale M, Della Chiesa M, Carlomagno S, Pende D, Arico M, Moretta L \& Moretta A. NK-dependent DC maturation is mediated by TNFalpha and IFNgamma released upon engagement of the NKp30 triggering receptor. Blood 2005106 566-571. (doi:10.1182/blood2004-10-4035)

29 Bjanesoy TE, Andreassen BK, Bratland E, Reiner A, Islam S, Husebye ES $\&$ Bakke M. Altered DNA methylation profile in Norwegian patients with autoimmune Addison's disease. Molecular Immunology 201459 208-216. (doi:10.1016/j.molimm.2014.02.018)

30 Kopp LM, Ray A, Denman CJ, Senyukov VS, Somanchi SS, Zhu S \& Lee DA. Decitabine has a biphasic effect on natural killer cell viability, phenotype, and function under proliferative conditions. Molecular Immunology 201354 296-301. (doi:10.1016/j. molimm.2012.12.012)

31 Triolo TM, Baschal EE, Armstrong TK, Toews CS, Fain PR, Rewers MJ, Yu L, Miao D, Eisenbarth GS, Gottlieb PA et al. Homozygosity of the polymorphism MICA5.1 identifies extreme risk of progression to overt adrenal insufficiency among 21-hydroxylase antibody-positive patients with type 1 diabetes. Journal of Clinical Endocrinology \& Metabolism 200994 4517-4523. (doi:10.1210/jc.2009-1308)

32 Whitaker MJ, Debono M, Huatan H, Merke DP, Arlt W \& Ross RJ. An oral multiparticulate, modified-release, hydrocortisone replacement therapy that provides physiological cortisol exposure. Clinical Endocrinology 201480 554-561. (doi:10.1111/cen.12316)

33 Mallappa A, Sinaii N, Kumar P, Whitaker MJ, Daley LA, Digweed D, Eckland DJ, Van Ryzin C, Nieman LK, Arlt W et al. A phase 2 study of Chronocort, a modified-release formulation of hydrocortisone, in the treatment of adults with classic congenital adrenal hyperplasia. Journal of Clinical Endocrinology and Metabolism 2015100 1137-1145. (doi:10.1210/jc.2014-3809)

Received 24 November 2016

Revised version received 16 January 2017

Accepted 23 January 2017 